\title{
Grupo Feliz Idade: cuidado de enfermagem para a promoção da saúde na terceira idade*
}

\author{
HAPPY AGE GROUP: NURSING CARE FOR THE PROMOTION OF HEALTH IN THE THIRD AGE \\ GRUPO FELIZ EDAD: CUIDADO DE ENFERMERIA PARALA PROMOCIÓN DE \\ LA SALUD EN LA TERCERA EDAD
}

\begin{abstract}
Janaína Fonseca Victor', Francisca de Fátima Vasconcelos", Adriana Rocha de Araújo"', Lorena Barbosa Ximenesiv, Thelma Leite de Araújov
\end{abstract}

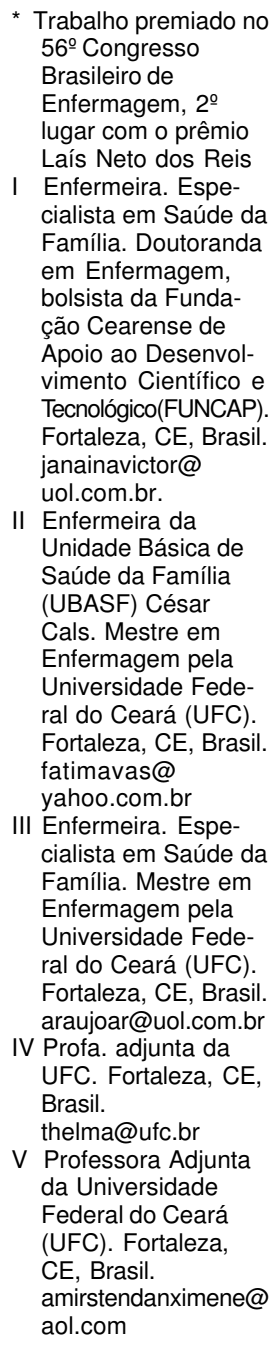

\section{RESUMO}

Este artigo teve como objetivos relatar a experiência da formação do grupo de idosos Feliz Idade, desenvolvido por enfermeiras do Programa Saúde da Família em Fortaleza-CE, bem como conhecer a importância do cuidado de enfermagem para a promoção da saúde na vida dos idosos. A seleção inicial dos participantes do grupo ocorreu entre os 314 idosos pertencentes aos programas de Hipertensão Arterial e Diabetes Mellitus. Para formação do grupo, as enfermeiras contaram com a colaboração de médico, fisioterapeuta, educador físico e agente de saúde. As atividades desenvolvidas no grupo foram caminhadas, oficinas, passeios e terapia comunitária. $\mathrm{O}$ grupo final foi formado por 124 idosos. Após a inserção destes idosos no grupo, ocorreram melhorias no aspecto biológico, como maior flexibilidade e melhor mobilidade articular, além da ampliação das interações sociais. Observa-se que as atividades, assim realizadas, favoreceram a promoção da saúde na terceira idade.

\section{DESCRITORES}

Enfermagem.

Promoção da saúde.

Idoso.

Saúde do idoso.

\section{ABSTRACT}

This article is aimed at describing the formation of the Happy Age, a group developed by nurses of the Family Health Program in the city of Fortaleza, State of Ceará, as well as to know the impact of the activities it carries out in the lives of senior citizens. The first participants of the group were 314 elders that are part of the Arterial Hypertension and Diabetes Mellitus programs. To form the group the nurses had the help of a doctor, a physiotherapist, a physical educator and a health agent. Group activities were walks, workshops, outings and community therapy. The final group was comprised of 124 members. After their insertion in the group, participants experienced improvements in the biological aspect, such as increased flexibility and better articulation mobility, in addition to increasing social interactions. It was observed that activities carried out this way favor the promotion of elderly citizen's health.

\section{KEY WORDS}

Nursing.

Health promotion.

Aged.

Health of the elderly.

\section{RESUMEN}

Este estudio tuvo como objetivo describir la formación del grupo de Feliz Edad, desarrollado por enfermeras del Programa Salud de la Familia en Fortaleza, Estado del Ceará, así como entender la importancia del cuidado de enfermería para la promoción de la salud en la vida de las personas mayores. Los participantes iniciales fueron escogidos entre los 314 ancianos del Programa Arterial Hipertesión y Diabetes Mellitus. Para la for-mación del grupo las enfermeras tuvieron ayuda del doctor, fisio-terapeuta, educador físico y agen-te de la salud. Fueron encami-nadas las actividades desarro-lladas por el grupo a oficinas, paseos y terapia en la comunidad. El grupo fue formado por 124 mayores. Después de la inserción en el grupo, ellos mejoraron en el aspecto biológico, como mayor flexibilidad y buena movilidad articular, además de aumentar y mejorar las interacciones sociales. Fue observado, que las actividades favorecieron la promoción de la salud en la tercera edad.

\section{DESCRIPTORES}

Enfermería.

Promocion de la salud.

Anciano.

Salud del anciano. 


\section{INTRODUÇÃO}

A população de idosos crescerá de tal modo que o Brasil será o $6^{\circ}$ do mundo, com aproximadamente 15 milhões de pessoas com 60 anos ou mais em 2025. Projeções recentes indicam ainda que, este segmento poderá chegar a quase $15 \%$ do contingente populacional em 2027, superando o número de crianças, e adolescentes com 14 anos ou menos. As previsões para a população de idosos revelam, que terão baixo nível educacional, viverão em áreas urbanas, com baixa renda familiar. Além desse quadro econômico e social, torna-se freqüente o aparecimento de doenças crônico-degenerativas com o aumento da expectativa de vida ${ }^{(1-2)}$.

De acordo com dados do Informe Epidemiológico do Sistema Único de Saúde (IESUS), a mortalidade por doenças do aparelho circulatório foi a primeira causa de morte entre os idosos brasileiros nas últimas décadas: em 1980, 44,7\% , em 1991, 40\% e em 1996, 38.1\% do total de óbitos. Em meio às principais doenças do aparelho circulatório, há um predomínio das doenças cerebrovasculares, seguidas pelas doenças isquêmicas do coração. Tais patologias foram as causas mais freqüentes de internações hospitalares, revertendose em gastos para o SUS, em torno de 23\%, com a referida população, ocorrendo, também, aumento nas reinternações que, em idosos, são cinco vezes maiores do que na faixa etária de 15 a 59 anos. Uma das principais estratégias de redução dessas doenças, segundo American Heart Association pode ser ações de promoção da saúde através de atividades físicas regulares ${ }^{(3)}$.

Pesquisa realizada sobre a produção científica brasileira em gerontologia, de 1975 a 1999, nas principais universidades, revelou existirem 232 trabalhos (188 dissertações, 39 teses de doutorado e cinco teses de livre docência), abordando temas relacionados aos aspectos clínicos (demência, Alzheimer, osteoartrite) e institucionais da velhice, não estando nenhum dos temas apresentados na perspectiva de investigar ações de promoção da saúde ${ }^{(4)}$.

$\mathrm{Na}$ área da Enfermagem, consideramos importante fazer um levantamento dos trabalhos apresentados nos Congressos Brasileiros de Enfermagem, nos anos de 1998, 1999, 2000, 2001, 2002 abordando o tema idoso, pelo fato daqueles serem eventos que viabilizam a divulgação e discussão de temas relevantes. Dentre os 285 trabalhos na área da saúde do idoso, apenas três trataram sobre o idoso numa perspectiva de grupo para promoção da saúde; 22 ainda enfatizaram grupo como estratégia para atividade de educação em saúde, principalmente, para controle de doenças crônicodegenerativas.
Reconhecendo que o trabalho de grupo pode ser uma estratégia que leva à promoção da saúde, alguns autores ${ }^{(5)}$ ressaltam que o trabalho do enfermeiro, desenvolvido com grupos, vem se constituindo em uma prática cada dia mais valorizada. Pesquisas demonstram que em grupo é mais fácil aprofundar discussões, ampliar conhecimentos sobre temas relacionados à saúde, conduzir processo de educação em saúde, estimular a adoção de hábitos saudáveis, contribuir para mudança de comportamento, além de promover a socialização do conhecimento em saúde.

Neste contexto, é oportuno lançar mão de estratégias que possam incrementar o cuidado de enfermagem na população de idosos, tendo em vista a importância do fenômeno do envelhecimento e do reconhecimento de que a dimensão do cuidar não se limita ao individual. Neste aspecto, o cuidado de enfermagem deve trabalhar propostas que contemplem a dimensão coletiva situando os indivíduos no processo de vida e morte, vislumbrando um olhar que não permita o isolamento do individuo no seu meio e no seu grupo de inserção ${ }^{(6)}$.

Observa-se uma preocupação maior em estudar as conseqüências e o impacto advindos dos custos para o tratamento das doenças que os idosos possam apresentar, do que com sua qualidade de vida (felicidade, satisfação com a vida e bem-estar), que representa um conceito ampliado de saúde ${ }^{(7)}$.

No cotidiano de nossas atividades profissionais no Programa Saúde da Família - (PSF) decidimos trabalhar em grupo com idosos, pois vivenciamos situações que nos despertaram quanto à necessidade de desenvolver estratégias que contemplassem o bem-estar, inte-rações sociais, elevação da auto-estima, além do sentimento de respeito e valorização. Muitas vezes, os idosos procuravam a unidade de saúde não para a realização de um atendimento específico, mas para conversar com os pacientes e funcionários. Pois se queixavam com frequiência da ausência de lazer na comunidade.

O trabalho em grupo permite compartilhar experiências e favorece o crescimento mútuo, dentre os tipos de grupos que podem ser formados, optamos pelo grupo operativo que tem como objetivo a promoção da saúde e visa proporcionar aos participantes bem-estar e aprendizagem em termos de resolução das dificuldades e problemas, além de encorajar a ajuda recíproca, em que cada um cuida de si, do outro, da comunidade e do meio ambiente, através de atividades físicas, recreativas, interativas e sociais ${ }^{(8)}$.

Nesse sentido, entendemos promoção da saúde como ações responsáveis pelo incremento das condições de saúde através de adoção de hábitos saudáveis, mudança no estilo de vida, visando a cidadania e inserção social ${ }^{(9)}$. 
Para tanto é preciso que os enfermeiros redimensionem o cuidar, especialmente, com grupos, interrompendo assim, planejamentos verticalizados, educação em saúde de caráter normativo, pouco efetiva e de pequeno impacto social.

Neste estudo, temos como objetivo relatar a experiência da formação do grupo Feliz Idade, desenvolvido por enfermeiras, bem como, conhecer a importância do cuidado de enfermagem para promoção da saúde na vida dos idosos do grupo.

\section{MÉTODO}

O estudo ora apresentado é um relato de experiência de natureza descritiva, que tem como objetivo relatar a experiência da formação do Grupo Feliz Idade e também conhecer a importância do cuidado de enfermagem para a promoção da saúde na percepção dos idosos. O estudo foi desenvolvido em uma Unidade Básica de Saúde da Família (UBASF), que assiste as famílias dos bairros Planalto Pici e Dom Lustosa, no município de Fortaleza-CE. Os referidos bairros estão inseridos na Secretária Executiva Regional III (SER III), cuja área abrange os bairros da Região Oeste de Fortaleza, com população estimada em 378.360 habitantes distribuídos em 16 bairros, dos quais 87,5\% apresentam condições socioeconômicas precárias.

Os participantes são os 124 idosos cadastrados no grupo Feliz Idade, que residem nos bairros anteriormente citados, que são atendidos pelas equipes do PSF. Utilizamos a definição de idoso, constante do art. $2^{\circ}$ da Lei $n^{\circ} 8.842 / 94$ : aquele indivíduo com 60 anos e mais. É importante ressalvar que não existe conceito universalmente aceitável com relação ao envelhecimento, sendo a idade cronológica, um dos mais utilizados para definir idoso e delimitar os participantes de um estudo ${ }^{(10)}$.

A partir da formação do grupo, iniciamos o cuidado de enfermagem com os idosos, através de atividades de alongamento, caminhada, dentre outras, utilizando continuamente, a observação participante e a entrevista informal, como formas de captar informações. A observação participante possibilitou apreender atitudes, olhares, que acompanhavam as falas dos sujeitos durante as atividades do grupo. Por conseguinte, realizamos entrevistas informais com os idosos abordando as mudanças que levaram à promoção da saúde durante as experiências vivenciadas entre idosos e enfermeiros.

Para registro das ações de enfermagem realizadas no grupo, foram utilizadas: gravação em fita cassete, fita VHS, diário de campo, com adoção de anotações telegráficas de palavras-chaves e fotografias.

Para desenvolver as atividades enviamos o projeto que foi avaliado e aprovado pelo Comitê de Ética em Pesquisa do Complexo Hospitalar da Universidade Federal do Ceará, seguindo as normas e diretrizes da Resolução 196/96 do Conselho Nacional de Saúde ${ }^{(11)}$, tendo os participantes assinado termo de consentimento (Processo CEP n. 128/01).

\section{COLABORADORES NA FORMAÇÃO DO GRUPO FELIZ IDADE}

O planejamento das atividades com o grupo de idosos contou com a parceria de alguns profissionais, que desenvolvem atividades no Centro de Cidadania como; médico, educador físico e fisioterapeuta. Essa ajuda possibilitou a escolha e adequação de atividades a esta população.

Os médicos das equipes do PSF apoiaram a formação do grupo e participaram com a avaliação quanto à aptidão para prática de atividades físicas (caminhadas e exercícios de alongamento). Aqueles que apresentaram contra-indicações na realização de atividades físicas, participaram das demais atividades (oficinas, atividades recreativas, passeios e terapia comunitária).

Os profissionais ora citados foram colaboradores e acreditaram no trabalho desenvolvido, no entanto, não participaram diretamente dos encontros do grupo Feliz Idade.

Utilizamos as recomendações de um estudo que incentiva atividades gratificantes, recreativas, motivadoras, integradoras e socializadoras $^{(12)}$. No que se refere às atividades recreativas utilizamos as técnicas de um outro estu$\mathrm{do}^{(13)}$. As técnicas escolhidas objetivam momentos lúdicos e de relaxamento como, por exemplos: brincadeiras com músicas e uso de bastões, balões e cordas. $\mathrm{O}$ fato de escolhermos literatura estrangeira, ocorreu pela escassa literatura nessa área no Brasil. Contudo, tivemos a preocupação de adaptar as atividades e orientações para o contexto de nossa população, respeitando crenças, valores, limitações e desejo dos participantes.

\section{DESCREVENDO AS ATIVIDADES DESENVOLVIDAS NO GRUPO FELIZ IDADE}

\section{Caminhadas}

A opção pela caminhada ocorreu pelo fato dos mesmos não apresentarem atividade física regular, o que pode potencializar as alterações do processo de envelhecimento. Para a prática da caminhada, orientamos sobre a importância de vestuário adequado, para prevenir traumas músculoesqueléticos, alimentação, hidratação, prática contínua e regular. Esta atividade era feita no horário da manhã, das 6:30h às 7:00h. Apesar do grupo constar de 124 idosos cadastrados, participaram da caminhada, em média, 70 idosos, pois alguns apresentavam contra-indicação na prática desta atividade. Havia ainda, os que eram resistentes em praticar atividade física. 


\section{Alongamento}

O alongamento foi uma estratégia escolhida para melhorar mobilidade e flexibilidade dos idosos do grupo, pois nesta idade a amplitude dos movimentos é limitada. Logo após a caminhada eram realizados exercícios de alongamento durante 30 minutos das, 7:00h às 7:30h. As atividades realizadas resultaram das recomendações da literatura consultada, e do próprio fisioterapeuta que fazia parte da equipe do Centro de Cidadania. Propusemo-nos, principalmente, a realizar exercícios de alongamento dos músculos cervicais, da coluna torácica e lombar, dos membros inferiores e superiores.

\section{Recreação}

Os idosos não dispunham de recursos na comunidade de atividades recreativas e de lazer. Sabe-se que a recreação, possibilita interações sociais, sentimentos agradáveis de alegria e bem-estar ${ }^{(5)}$. Procuramos realizar as atividades recreativas após o alongamento, de forma lúdica, resgatando brincadeiras e músicas conhecidas pelos idosos da sua infância e adolescência, trazendo a tona sentimentos e lembranças positivas, sendo sugeridas, tanto pelo grupo, quanto pelas enfermeiras.

Importante salientar, que por iniciativa dos idosos, ao final das atividades era formada uma grande roda com todos de mãos dadas, em que os mesmos manifestavam a sua espiritualidade, através de cânticos e orações, agradecendo as experiências vividas no grupo, fortalecendo os laços afetivos e sentimentos positivos.

\section{Atividades Comemorativas}

A atividade comemorativa, muitas vezes, não era festejada entre os idosos, seus familiares e pessoas significativas que faziam parte de sua história de vida. Por isso, procuramos comemorar as datas festivas no final de cada mês, em que festejamos os aniversariantes do mês em curso, como também, carnaval, dia das mães, festas juninas, dia dos pais, dia do idoso e natal e aniversário do grupo. Grande parte das atividades era registrada em vídeo e fotografia, tendo se tornado um recurso importante, pois os idosos manifestavam sentimentos positivos ao rever suas imagens. As atividades comemorativas eram responsáveis em congregar o maior número de idosos, com participação efetiva tanto na organização como na execução das atividades, procurando resgatar suas possibilidades de autonomia e auto-estima.

\section{Oficinas}

As oficinas eram desenvolvidas com os idosos, a fim de discutir assuntos da comunidade, como drogas, violência, qualidade de vida, relações familiares, doenças crônico-degenerativas e sistema de saúde local, escolhidas pelo próprio grupo. As oficinas eram agendadas em horários extras, geralmente, às sextas-feiras, na freqüência de uma por mês. O número de participantes oscilava entre 30 a 40 idosos.

\section{Passeios}

Muitos idosos não tinham condições financeiras de se deslocar da comunidade para outros locais significativos que desejavam conhecer. Por isso, sempre se programavam passeios conforme o desejo dos participantes, selecionando o local a ser conhecido. O primeiro local que visitamos foi a praia, já que apesar de morarem em uma cidade litorânea, muitos deles não conheciam o mar. Os outros passeios foram para as seguintes cidades do Ceará: Canindé (local de culto a São Francisco de Assis), pontos turísticos de Fortaleza, colônia de férias em Iparana, Serra de Guaramiranga e Balneário das Andréas, em Pacatuba. Os passeios ocorriam com a parceria entre a unidade de saúde, o Centro de Cidadania e a Secretaria Executiva Regional III. Quase todos os idosos cadastrados participaram dos passeios.

\section{Terapia Comunitária}

No decorrer das ações desenvolvidas no grupo, buscamos também, motivar os idosos para superar as dificuldades dos problemas cotidianos, através da realização da Terapia Comunitária Sistêmica Integrativa. Esta utilizava a competência das pessoas e promovia a construção de redes sociais, com ênfase no trabalho de grupo em que os participantes, juntos, buscavam soluções para os problemas cotidianos, podendo funcionar como escudo protetor para os mais frágeis, sendo instrumento de agregação social ${ }^{(14)}$.

A escolha por essa terapia ocorreu, pelo referido autor ser professor do Departamento de Saúde Comunitária da Universidade Federal do Ceará, na qual uma das enfermeiras era residente em saúde da família, tendo sido treinada para aplicar esta terapia junto ao grupo.

As atividades acima descritas constituíram o cuidado de enfermagem, pois estabeleceram uma relação dialógica proporcionando o desenvolvimento de cada um, aproximandoos da satisfação das necessidades existentes, extrapolando a dimensão tecnicista do cuidado ${ }^{(6)}$.

\section{FORMAÇÃO DO GRUPO FELIZ IDADE}

Dentre os 314 pacientes idosos acompanhados na UBASF nos programas de Hipertensão Arterial Sistêmica (HAS) e Diabetes Mellitus (DM), 62 idosos foram os primeiros participantes selecionados para o grupo Feliz Idade, que apresentavam baixa adesão ao tratamento medicamentoso, ausência de atividades sociais, recreativas e interações familiares, além de verbalização de sentimentos relacionados as perdas reais e percebidas pelo processo de envelhecimento. 
Importante salientar, que as condições citadas foram utilizadas, inicialmente, para selecionar os primeiros idosos no grupo e posteriormente estes requisitos não foram o foco de atenção para que demais idosos pudessem ingressar. Além de que, as atividades desenvolvidas no grupo não se limitaram às condições previamente estabelecidas para a seleção, visto que, o cuidado de enfermagem resultou de uma relação dialógica entre os idosos e os enfermeiros em um processo dinâmico na satisfação de suas reais necessidades.

Durante o mês de junho de 2001 as enfermeiras se reuniram com os agentes de saúde, para discutir a formação do grupo, por acreditarem que estes profissionais seriam elementos-chave, na mobilização de pessoas na comunidade. Logo, estes realizaram visitas domiciliárias aos 62 idosos pré-selecionados para compor o grupo, com objetivo de convidá-los a participarem de uma reunião com as enfermeiras da UBASF.

No momento da realização da reunião, tivemos a presença de 24 idosos, em que tivemos a oportunidade de esclarecer a proposta de formação do grupo como estratégia de cuidar para promoção da saúde, tendo boa aceitação por parte dos mesmos.

Durante a reunião, foi firmado um contrato verbal, em que escolhemos, junto com os idosos, as atividades que seriam realizadas (atividades físicas, recreativas e oficinas), visto que estas ratificam as recomendações da literatura e das próprias necessidades que foram discutidas com os mesmos. Logo, estabelecemos a data de início da primeira atividade (junho de 2001), com dias e horários, de acordo com a disponibilidade dos idosos, terças e quintas-feiras das 07:00h às 08:30h.

Os encontros iniciais ocorreram no campo de futebol e no auditório do Centro de Cidadania César Cals, para a realização das atividades físicas. Em relação às demais atividades, seguimos o cronograma de datas comemorativas (dia das mães, dia dos pais, festas juninas, carnaval, dia do idoso, Natal, dentre outras). As oficinas foram realizadas de acordo com a necessidade do grupo em aprofundar algum tema específico.

As atividades desenvolvidas no grupo de idosos aconteceram na Unidade Básica de Saúde da Família (UBASF) que está inserida em um Centro de Cidadania que dispõe de recursos sociais e educativos como creche, escola, cursos profissionalizantes, além de aulas de ginástica, hidroginástica, capoeira e balé, facilitando o desenvolvimento das atividades que realizamos no grupo, pois a estrutura ainda dispõe de quadra de esporte, campo de futebol, auditório e piscina olímpica.
Na primeira atividade realizada apenas três idosos compareceram, No encontro seguinte, o número aumentou para 12, em duas semanas eram 35 idosos. Este fato ocorreu porque os participantes começaram a divulgar de forma positiva as atividades, tanto no contexto familiar quanto na própria unidade de saúde (salas de preparo e de espera), incentivando que novas pessoas procurassem as enfermeiras para que pudessem se engajar no grupo. Sendo assim, o grupo deixou de estar vinculado aos portadores de hipertensão e diabetes, passando a receber novos idosos com ou sem doenças crônicas degenerativas, mas que partilhavam de problemas semelhantes devido ao processo do envelhecimento, como também, por estarem inseridos no mesmo contexto social. Em apenas três meses já havia 80 idosos e, ao final do primeiro ano, 106 idosos participavam das atividades. Após três anos de atividades, o grupo conta atualmente com a participação de 124 idosos cadastrados.
As atividades

desenvolvidas

no grupo não se

limitaram às

condições

previamente

estabelecidas para

a seleção, visto que

o cuidado de

fermagem resultou

de uma relação

dialógica entre

os idosos e

os enfermeiros...

Os idosos participantes do grupo são cadastrados em um formulário próprio, com foto e dados referentes a: idade, sexo, problemas de saúde, agente de saúde responsável pelo acompanhamento, dados do domicilio e da família; este recurso facilita o acompanhamento dos participantes do grupo.

Importante ressaltar, que as enfermeiras atuam como facilitadoras, deixando o grupo tomar decisões, quanto à programação das atividades, desde a escolha do nome do grupo (Feliz Idade), como os locais a serem visitados e as atividades que são desenvolvidas. Por ser constituído por muitos participantes surgem conflitos, como por exemplo, no momento da escolha dos lugares a serem visitados ou dos trajes nas festas comemorativas, em virtude de algumas situações desse tipo, seis idosos assumiram espontaneamente a responsabilidade de mediar discussões e atuam como líderes, pois são membros da pastoral do idoso, conhecem quase todos os participantes, possuindo um jeito próprio de lidar com situações divergências.

\section{IMPORTÂNCIA DO CUIDADO DE ENFERMAGEM PARA A PROMOÇÃO DA SAÚDE NA PERCEPÇÃO DOS IDOSOS}

No sentido de avaliar o impacto das atividades na vida dos idosos participantes do grupo, sempre procuramos resgatar, a partir das entrevistas informais com os idosos, questões sobre a importância do grupo para a sua vida e o que este representa na promoção da sua saúde. As falas foram transcritas e agrupadas de acordo com a convergência . A partir dessas vivências relatadas, procuramos compreender o modo como as atividades do grupo têm promovido a saú- 
de destes, o que resultou neste estudo a construção de duas categorias: promoção da saúde física e promoção da socialização.

\section{Promoção da saúde física}

O organismo envelhece transforma-se e vai perdendo suas competências. À medida que os anos passam essas transformações vão sendo acentuadas e podem gerar doenças como artrose, problemas cardiovasculares, respiratórios, obesidade, ansiedade, depressão, dentre outras. Diante de todas essas possíveis alterações, a atividade física age positivamente, seja como forma de prevenção de doenças ou manutenção da saúde ${ }^{(12-13)}$.

Muitos dos idosos relataram a importância do grupo em suas vidas, enfocando a melhoria no aspecto biológico, pois muitos deles já tinham alterações físicas que comprometiam $o$ atendimento de suas necessidades.

\begin{abstract}
Depois do grupo mudou muita coisa minha saúde está melhor, eu sentia reumatismo, não podia nem andar, agora me sinto melhor, eu tinha pensamentos tristes, agora não.

Se não tivesse participado do grupo já teria morrido, pois era muito nervoso, vivia com dor de cabeça, depois do grupo deixei de fumar, os meus filhos estão achando que melhorei demais eu era muito abusado.

Eu fico alegre quando venho, prá mim seria muito bom que fosse três dias na semana, estou perdendo peso, eu era muito gorda tinha $96 \mathrm{Kg}$ e agora estou com $80 \mathrm{Kg}$.

Eu vivia doente das pernas, dos braços eu melhorei muito...representa uma vida nova, uma coisa muito boa, me sinto muito mais saudável, antes chorava com dores nas pernas e hoje não tenho mais, estou me sentindo mais disposto e isso me deixa muito satisfeito.
\end{abstract}

Ao iniciar, continuar ou potencializar atividade física, o idoso experimenta uma mudança significativa em sua vida, ajudando a aumentar o seu equilíbrio pessoal, melhorando o seu estado de ânimo, sua mobilidade, seus reflexos, sua postura e agilidade, influenciando, assim, na sua qualidade de vida.

A mobilidade articular diminui devido às transformações degenerativas e o desuso. A prática de exercício adequado possibilita uma melhoria na amplitude do movimento articular, tanto em flexão como em extensão, permitindo a realização de atividades comuns da vida diária, freqüentemente impossibilitada nos idosos sedentários, por diminuição da flexibilidade ${ }^{(12)}$.

A partir destes relatos, pudemos perceber o quanto à Enfermagem atuando numa perspectiva de promoção da saúde pode desenvolver ações eficazes não só voltadas para as condições físicas dos idosos do grupo (melhorando o andar prejudicado e a mobilidade física prejudicada), como, possibilitar que os mesmos construam uma nova maneira de se cuidarem, no sentido de adotar hábitos saudáveis que repercutirão no seu estilo de vida.

\section{Promoção da socialização}

Um dos problemas de Enfermagem percebidos em idosos é o risco para a solidão, em que muitos perderam seu núcleo social de trabalho. Ao se aposentarem, alguns deles ficaram viúvos, perdendo seus entes queridos e geralmente seus filhos já saíram de casa. Neste contexto, as atividades em grupo podem ajudar a superar esses problemas, já que o grupo permite atividades sociais, relacionais e de movimentos ${ }^{(12)}$.

$\mathrm{Na}$ terceira idade, as atividades sociais constituem aberturas para o estabelecimento de novos canais de comunicação entre as pessoas. O engajamento em atividade de grupo, tem mostrado mudanças no comportamento dos idosos, principalmente, no círculo de amizade, que é ampliado, contribuindo assim, para romper situações de solidão ${ }^{(12-13)}$.

Os relatos dos idosos que têm experienciado o trabalho em grupo, ratificam as considerações dos autores acima citados quanto à melhoria da integração social dos mesmos.

\footnotetext{
Parece que eu vivia dentro de uma gaiola, agora as minhas asas estão se soltando.
}

O grupo trouxe muitos benefícios é como se eu tivesse revivido, eu não saia de casa e o grupo me tirou de casa, a minha juventude foi só de trabalho, em casa, fui criar minhas filhas e netas e o grupo me trouxe de volta metade da vida que eu tinha perdido, eu me sentia mas velha do que eu era....

O dia que eu não venho fico logo triste, já acordo com coragem para vir para o grupo, mais disposição, todo mundo acha que está ficando mais novo é uma forma de crescimento, ficamos mais próximo do posto, representa uma família, é como se adquirisse mas uma família.

Eu era muito solitária não tinha amizade. O grupo me ajudou, gosto de brincar ser alegre. O grupo melhorou meu relacionamento principalmente familiar. A alegria do grupo me faz muito bem.

A participação de idosos em atividades em grupo, representa um aspecto diferencial, no rumo de suas histórias de vida, pois favorece a vivência de um estado de plenitude e bem-estar, que possibilita um reforço em seu sentido existencial, ajudando a perceber seu futuro como uma história em construção ${ }^{(5-15)}$.

Em idosos, em particular, a convivência em grupo é importante para um perfeito equilíbrio biopsicossocial, reduzindo ou removendo conflitos pessoais e ambientais, facilitando a socialização e oferecendo suporte social para enfrentar as dificuldades que surgem com o envelhecimento. Contribui, dessa forma, para uma melhor qualidade de $\operatorname{vida}^{(12-13)}$. 
Sendo assim, pudemos observar que os idosos, realmente, não tinham uma vida de socialização adequada para a satisfação de seus anseios. E com as atividades em grupo, constatamos que os mesmos conseguiram reencontrar diferentes modos de viver que vieram proporcionar-lhes resgate de valores, cuja falta já não era sequer, notada por eles.

\section{CONSIDERAÇÕES FINAIS}

O enfermeiro, no cotidiano de suas atividades, deve agir com equidade nas escolhas de suas intervenções, pois os indivíduos, dependendo do estágio de vida que se encontram, possuem necessidades específicas, que precisam ser atendidas de forma diferenciada, e o grupo pode ser um elemento facilitador para o processo de cuidar na promoção da saúde.

O trabalho de Enfermagem desenvolvido no grupo Feliz Idade trouxe mudanças significativas nos aspectos bio-

\section{REFERÊNCIAS}

1. Brasil. Ministério da Previdência e Assistência Social. Idosos: problemas e cuidados básicos. Brasília; 2002.

2. Souza JN, Chaves EC. O efeito do exercício de estimulação da memória em idosos saudáveis. Rev Esc Enferm USP. 2005;39(1):13-9.

3. Lima e Costa FMF, Guerra HL, Barreto SM, Guimarães RM. Diagnóstico da situação de saúde da população idosa brasileira: um estudo da mortalidade e das internações públicas. Inf Epidemiol SUS. 2000;9(1):23-41.

4. Goldstein LL. A produção científica brasileira na área da gerontologia: (1975 - 1999). Rev Online Bibli Prof Joel Martins [periódico na Internet]. 1999 [citado 2004 jan. 10];1(1):[cerca de $5 \mathrm{p}$ ]. Disponível em: http://www.bibli.fae.unicamp.br/ revgeron/llg.htm

5. Silva DGV, Francioni, FF, Natividade SL, Azevedo M, Andoval RCB, Di'Lourenzo VM. Grupos como possibilidade de desenvolver educação em saúde. Texto Contexto Enferm. 2003; 12(1):97-103.

6. Rossi FR, Silva MAD. Fundamentos para processos gerenciais na prática do cuidado. Rev Esc Enferm USP. 2005;39(4):460-8.

7. Veras R. Terceira idade: alternativas para uma sociedade em transição. Rio de Janeiro: Relume-Dumará; 1999. psicossociais dos participantes, uma vez que não se limitou a utilizar práticas normativas, repetitivas e verticalizadas, e sim, a participação efetiva dos sujeitos, estimulando-os a autonomia na realização das atividades, pois mesmo na ausência das enfermeiras, se reúnem em grupo.

Outro aspecto a ser considerado foi a valorizações dos idosos no Centro de Cidadania, após a formação do grupo Feliz Idade, quando outros profissionais despertaram para a atenção ao idoso, proporcionando horários específicos, para hidroginástica e atendimento odontológico, os quais não tinham acesso anteriormente.

A Enfermagem possui um inefável poder de criatividade na execução do cuidado, tanto individual quanto em grupo, utilizando estratégias que favorecem a alegria, o bem-estar, a felicidade. Nesse sentindo estratégias devem ser estimuladas, para a promoção da saúde, em especial, na terceira idade.

8. Pichon-Reviere E. O processo grupal. $6^{\mathrm{a}}$ ed. São Paulo: Martins Fontes; 2000.

9. Jacob Filho W. Promoção da saúde do idoso. São Paulo: Lemos; 1998.

10. Santos SSC. Enfermagem gerontogeriátrica: da reflexão à ação cuidativa. $2^{\text {a }}$ ed. São Paulo: Robe; 2001.

11. Conselho Nacional de Saúde. Resolução n. 196, de 10 de outubro de 96. Dispõe sobre diretrizes e normas regulamentadoras de pesquisas envolvendo seres humanos. Bioética. 1996;4(2 Supl): $15-25$.

12. Geis PP. Tercera edad, actividad física y salud: teoría e práctica. Lisboa: Paidotribo; 2001.

13. Geis PP, Rubi MC. Movimiento creativo com personas mayores: recursos prácticos para montar tus sesiones. Lisboa: Paidotribo; 2001.

14. Barreto A. Terapia comunitária passo a passo. Fortaleza: Departamento de Saúde Comunitária, Faculdade de Medicina/ UFC; 2003.

15. Papaléo Neto M, Ponte JR. Envelhecimento: desafio na transição do século. $2^{\mathrm{a}}$ ed. São Paulo: Atheneu; 1996. 